\title{
ENSINO DE LÍNGUA E LITERATURA
}

É com satisfação que a Revista de Letras da UTFPR-Curitiba, do Departamento Acadêmico de Linguagem e Comunicação - DALIC, traz a público a edição "Dossiê temático: Ensino de Língua e Literatura", Volume 19, n.26, ano set./2017, organizado em conjunto pelas Professoras Doutoras Alice Atsuko Matsuda, da UTFPR-Curitiba, Vanderléia da Silva Oliveira, da UENP-Cornélio Procópio, com a colaboração da Doutora Ana Maria e Silva Machado e o Doutor José Augusto Cardoso Bernardes, do Centro de Literatura Portuguesa, da Faculdade de Letras da Universidade de Coimbra.

O dossiê se propôs a acolher estudos voltados às questões que envolvem o ensino de Língua Portuguesa e da Literatura, de modo a apontar alguns caminhos e respostas a várias delas como possibilidades/alternativas teóricas e metodológicas, e que pudessem colaborar para a socialização dos estudos realizados em diferentes contextos. Como resultado, os oito textos aqui selecionados são de autoria de pesquisadores(as) que estão vinculados(as) a várias universidades brasileiras - Universidade Federal do Amazonas (UFA), Universidade Federal do Rio de Janeiro (UFRJ), Faculdade CNEC Ilha do Governador, Centro Federal de Educação Tecnológica de Minas Gerais ( CEFETMG Campus Divinópolis), Universidade de Caxias do Sul, Caxias do Sul, Universidade do Oeste do Paraná (UNIOESTE), Universidade Estadual de Maringá (UEM), Universidade Federal de Alagoas (UFAL), Instituto Federal de Santa Catarina e Universidade Federal de Santa Catarina (UFSC).

Deste modo, com foco na abordagem da literatura em sala de aula, no texto "A literatura infantil em sala de aula nos anos iniciais: a importância dos contos", as autoras Tiana Andreza Melo Antunes e Thaís Martins de Oliveira se voltam para a literatura infantil e colocam em relevo o uso do gênero conto no espaço escolar no processo de formação do leitor e apresentam a percepção dos professores com relação à abordagem realizada nas escolas com os textos literários. Também no âmbito dos estudos sobre formação de leitores, Rodrigo Alves dos Santos, em "Elementos para começar uma conversa sobre a formação de formadores de leitores críticos de textos literários para atuação no ensino médio", provoca-nos a refletir sobre diversas tensões que envolvem a presença do texto literário em sala de aula, a fim de, dentre outros aspectos, oportunizar discussões sobre a formação de professores de Língua Portuguesa, especialmente quanto à abordagem da literatura no ensino médio.

Ainda com o olhar voltado para o texto literário, com foco na literatura infanto-juvenil, o texto "Literatura e memória: uma proposta de letramento literário para o conto popular no ensino fundamental", de Edivana Cássia Munhoz Suriano e Margarida da Silveira Corsi, se volta para o repertório folclórico com destaque para a relevância das narrativas e a divulgação da cultura oral em ambiente escolar. Também, a partir do gênero memória, tendo como objetivo oferecer ao leitor reflexões sobre como o docente pode promover situações que instrumentalizem os alunos a produzirem e a reescreverem seus 
textos de modo a observar os fatores de coesão e de coerência, as autoras Fabiana Kaodoinski e Neires Maria Soldatelli Paviani apresentam o texto "Escrita e reescrita do gênero textual memória literária: estratégias para melhoria da coesão e da coerência", a partir de um estudo de caso.

No texto "A importância da abordagem sociolinguística para a formação do professor de Língua Portuguesa", de autoria de Andreza Marcião dos Santos, Ana Cláudia Fernandes Nogueira e Aldair Oliveira de Andrade, toma-se como objeto de análise a variação linguística para defesa da presença da Sociolinguística nos cursos de formação de professores, a fim de oferecer a eles melhores condições teóricas para o trabalho em sala de aula. Angela Dondoni e Maria Elena Pires Santos, em "Estratégias metacognitivas de leitura na escola", tendo como ponto de partida os resultados de pesquisa com professores de diferentes disciplinas de uma escola pública, analisam quais estratégias eles utilizam em suas leituras e como as usam (ou não) junto a seus alunos nos processos de ensino e aprendizagem. Por sua vez, Silvio Nunes da Silva Júnior, em "Oralidade e letramento no ensino de língua portuguesa: reflexões sobre o uso dos gêneros do discurso em sala de aula", se propõe a discutir sobre as atividades de letramento no ensino de língua portuguesa com a utilização dos gêneros debate e conto como forma de contribuição para a formação dos alunos em situações de aprendizagem. Por fim, voltando-se para a Lexicografia e o uso dos dicionários bilíngues na sala de aula do aprendiz de línguas, e mais especificamente de inglês como língua estrangeira, Caroline Chioquetta Lorenset e Adja Balbino de Amorim Barbieri Durão apresentam ao leitor o texto "Sobre o uso dos dicionários por alunos do ensino médio".

Esperamos que o dossiê atenda às expectativas dos leitores interessados neste tema e aproveitamos para agradecer aos pareceristas ad hoc, da UTFPR e oriundos de diversas outras instituições do país, pela colaboração na avaliação dos artigos. O agradecimento é extensivo aos colaboradores que auxiliaram na editoração do volume.

Editora-chefe Profa. Dra. Alice Atsuko Matsuda (UTFPR-Curitiba/PPGEL/FLUC-Capes) 